\title{
'Doing the right thing wrong' - Personality and tolerance to uncomfortable robot approaches
}

\author{
Dag Sverre Syrdal, Kerstin Dautenhahn, Sarah Woods, Michael L. Walters, Kheng Lee Koay
}

\begin{abstract}
The study presented in this paper explored the relationships between subject personality and preferences in the direction from which a robot approached the human participants $(\mathrm{N}=42)$ in order to deliver an object in a naturalistic 'living room' setting. Personality was assessed using the Big Five Domain Scale. No consistent significant relationships were found between personality traits and preferred approach directions; however, a consistent nonsignificant trend was found in which high scores on the personality trait extraversion was associated with a higher degree of tolerance to the approach directions rated overall as most uncomfortable. The implications of the results are discussed both from a theoretical and methodological viewpoint.
\end{abstract}

Index Terms - Human robot interaction, live trials, social robotics, personality, extraversion

\section{INTRODUCTION}

The work presented in this paper has been carried out as part of the European project Cogniron. The purpose of Cogniron is to study the perceptual, representational and learning capabilities of robots in human centred environments in order to develop methods and technologies for the construction of robots capable of adapting and growing their capacities in close interaction with humans in an open-ended fashion [1]. In the context of the Cogniron project a Robot Companion must fulfill two important functions: a) making itself 'useful', i.e. being able to carry out a variety of tasks in order to assist humans in a domestic home environment, and b) behaving socially, i.e. possessing social skills in order to be able to interact with people in a socially acceptable manner.

In order to achieve the second goal, we have conducted several studies that addressed the relative comfort that subjects experienced in human-robot interactions depending on the robot's behaviour [2-5]. Results from this work contribute to a set of 'social rules' that we develop for a robot companion. However, the rules must also be adaptive in order to account for different user preferences, as well as

Manuscript received March 31, 2006. The work described in this paper was conducted within the EU Integrated Project COGNIRON("The Cognitive

Robot Companion") and was funded by the European Commission Division FP6-IST Future and Emerging Technologies under Contract FP6-002020 Dag Sverre Syrdal, Kerstin Dautenhahn, Sarah Woods, Michael L. Walters, Kheng Lee Koay. Adaptive Systems Research Group, School of Computer Science, University of Hertfordshire, Hatfield, Herts. UK (D.S.Syrdal, K.Dautenhahn, S.N.Woods, M.L.Walters, K.L.Koay)@herts.ac.uk. long-term effects of habituation. The issue of personalisation and adaptivity which are necessary for a personalised robot companion [6] where a robot can adapt to a human's likes, dislikes and preferences, is still an open issue in robotics. In the related field of Human - Computer Interaction, these issues have traditionally been addressed by examining the different needs that a system has to meet on the basis of the users' expertise, familiarity with the system, work role and accessibility issues. However, there have been very few examples of systems that have taken into account the user's personality traits in the design of adaptive systems [7], although some studies have found consistent effects of personality in the use of specific interfaces $[8,9]$ and virtual agents [10].

In a domestic setting, e.g. a robot operating in a person's home, personality may be an issue for human-robot interaction to a much larger extent than in work or public settings such as museums. Such interactions will not be as limited in time and scope as in the public settings [11, 12] and as such the need for personalisation may be greater to ensure that the manner a social robot performs its tasks is appropriate not only to the task and the setting of the task but also to the personal preferences and expectations of the individual user.

The study of user personality and its impact on human robot interaction is a new field. Nomura \& Kanda [13] proposed a robot anxiety scale to measure anxiety in relation to robots and this scale was then used to investigate the relationship between such anxiety and participant behaviour towards robots [14]. These studies have so far not yielded any clear, consistent links between this scale and subjects' behaviour.

This study is an investigation into the possible link between personality and the preferred direction of approach for a robot approaching the participant in a helping scenario (fetch and carry task).

As a first HRI study into the relationships between subject personality and robot behaviour, we previously investigated the relationship between personality and preferred approach distances [3] where we found a negative correlation between 'Proactiveness' and approach distances, i.e. more 'Proactive' participants preferred not to approach a mechanistic robot to as close a distance as less 'Proactive' participants. In these experiments distance ratings were achieved by human subjects approaching a stationary robot 
in a straight line, and vice versa, without any interaction involved other than the physical approach.

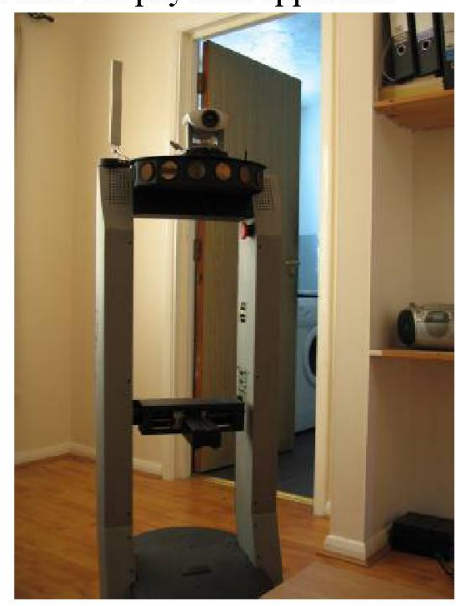

Fig 1 . The Peoplebot ${ }^{\mathrm{TM}}$ robot used in the study.

Other researchers studying the effect of robot facilitation of human task-related behaviour [15], found a small, nonsignificant correlation between the personality trait of extraversion and tolerance to robot proximity in a postinteraction evaluation questionnaire, in a scenario where a small Pioneer 2-DX robot mirrored the behaviour of a participant.

In the present study, a mechanistic robot approached participants, to a distance of about $20 \mathrm{~cm}$, from different directions in order to offer a snack. Our interest was in the effect of participant personality on the reported comfort ratings for each approach direction.

The personality model we used in this study was the Big Five Model, measured using the Big Five Domain Scale from IPIP [16]. This model is used extensively in psychological research, which means that results obtained through the use of this model easily can be compared to those of other psychological studies. The Big Five model assumes five basic personality factors (See table 1 for a brief description of correlates for the different factors).

TABLE 1 BIG FIVE PERSONALITY FACTORS ( ADAPTED FROM [17])

\begin{tabular}{ll}
\hline \hline Emotional Stability & $\begin{array}{l}\text { Anxiety, depression, self-consciousness, } \\
\text { impulsiveness, vulnerability }\end{array}$ \\
Warmth, gregariousness, assertiveness, activity, \\
Extraversion & $\begin{array}{l}\text { Trustement seeking, positive emotions } \\
\text { compliance, modesty, tender-mindedness }\end{array}$ \\
Agreeableness & $\begin{array}{l}\text { Competence, order, dutifulness, achievement } \\
\text { striving, self-discipline, deliberation } \\
\text { Conscientiousness } \\
\text { Intellect } \\
\text { Interests }\end{array}$ \\
\hline \hline
\end{tabular}

\section{METHOD}

\section{A. Participants:}

The 42 human participants in this study were drawn from the students and staff at the University of Hertfordshire. There were 27 males and 15 females participants, ranging from 18 to 56 years of age (Median age was 25). Consent for participation was obtained in writing and participation was voluntary and unpaid.

\section{B. Apparatus}

The robot used for this particular study was a PeopleBot ${ }^{\mathrm{TM}}$ (commercially available from ActivMedia Robotics). The PeopleBot ${ }^{\mathrm{TM}}$ is human-sized and mechanistic in appearance. The robot was in this study operated under remote control, a method known as the Wizard of Oz Method [18].

Personality traits and comfort ratings for the various approach conditions were assessed using a pen and paper questionnaire.

The Big Five Domain Scale measures the participants' responses to 10 items relating to each of the five factors which are then added together in order to create a scale for each factor. For a more in depth discussion on the rationale for the scales and their validation, see [16]. Please refer to table 2 below for sample questions. The responses to the items were recorded on a 5 point Likert scale, where 1 was 'completely disagree' and 5 was 'completely agree'. TABLE 2 SAMPLE ITEMS FROM THE BIG FIVE DOMAחN SCALE

\begin{tabular}{ll}
\hline \hline Emotional Stability & I am relaxed most of the time. \\
I get stressed easily. \\
I am the life of the party. \\
I am quiet around strangers. \\
Agreeableness & I sympathise with others' \\
& feelings. \\
I feel little concern for others. \\
I am always prepared. \\
I leave my belongings around. \\
I use difficult words. \\
Intellect & ideas.
\end{tabular}

C. Experimental Procedure:

1) Setup

The experiment took place in the Robot House, a flat rented by our research group for the purpose of allowing the trials to take place in a more naturalistic environment (as opposed to a laboratory setting), closely resembling a normal home. The participants were shown around the flat and then watched the introduction video on the sofa of the living room. After this, the participants were asked to fill out the personality and demographics questionnaires as well as sign the consent form.

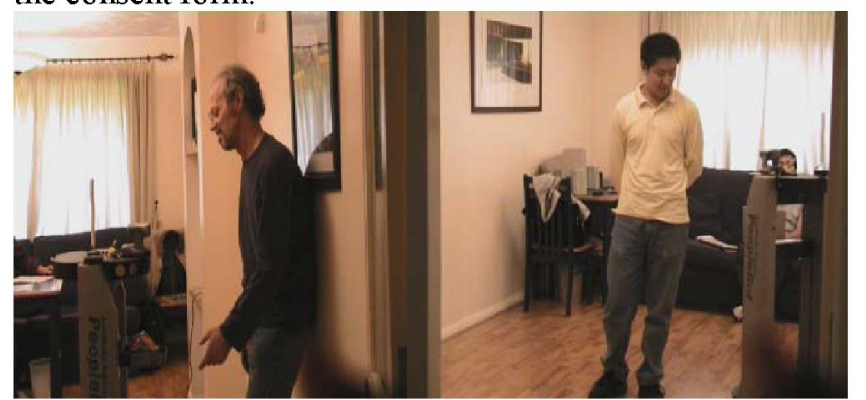

Fig. 2. Scenarios involving participants standing against a wall (left), and in the middle of the room (left). 
2) Robot Approaches:

This experiment was divided into four scenarios. In each of these scenarios, the robot approached the participant to offer a snack (a bag of crisps held in the robot's gripper). The scenarios differed in the position of the participant, and in each scenario the robot approached from different directions (see table 3).

\begin{tabular}{|c|c|c|}
\hline $\begin{array}{l}\text { Scenari } \\
0\end{array}$ & $\begin{array}{l}\text { Participant } \\
\text { Position }\end{array}$ & $\begin{array}{l}\text { Robot } \\
\text { Directions }\end{array}$ \\
\hline 1 & Seated behind table & $\begin{array}{l}\text { Front Left, Front Right, Front } \\
\text { Direct, Rear Left and Rear Right }\end{array}$ \\
\hline 2 & Seated without table & $\begin{array}{l}\text { Front Left, Front Right, Front } \\
\text { Direct, Rear Left and Rear Right }\end{array}$ \\
\hline 3 & $\begin{array}{l}\text { Standing w/back } \\
\text { against the wall. }\end{array}$ & $\begin{array}{l}\text { Front Left, Front Right, Front } \\
\text { Direct }\end{array}$ \\
\hline 4 & $\begin{array}{l}\text { Standing in the } \\
\text { middle of the room. }\end{array}$ & $\begin{array}{l}\text { Front Left, Front Right, Front } \\
\text { Direct, Rear Left and Rear Right, } \\
\text { Rear Central. }\end{array}$ \\
\hline
\end{tabular}

${ }_{4}^{+1}$

Fig 3. Robot approach directions to participant (P) are as follows: Front Left (1), Front Direct (2), Front Right (3), Rear Left (4), Rear Central (5), Rear Right (6).

The sample was randomly divided into two groups. Group 1 participated in Scenarios 1 and 3, while group 2 participated in Scenarios 2 and 4 . The order of the scenarios and the sequence of approach directions within the scenarios were randomised for each participant.

3) Evaluation of approach directions:

After the completion of each scenario, the participants were invited to fill in a questionnaire asking them to rate the different approach directions on a five point Likert scale on how comfortable the particular direction was compared to the other directions.

\section{Results}

\section{A. General for approach directions:}

\section{a) Seated at table scenario:}

Non-parametric Friedman tests were carried out which found significant differences in mean comfort rating between the different approach directions $\left(\mathrm{Chi}^{2}(4)=26.05\right.$, $\mathrm{p}<.001)$. The Front Right and Front Left directions were rated as the most comfortable, while the rear approaches were rated as the least comfortable. b) Seated w/out table scenario:

Non-parametric Friedman tests were carried out which found significant differences in mean comfort rating between the different approach directions $\left(\mathrm{Chi}^{2}(4)=19.39\right.$, $p<.001)$. The Front Right and Front Left directions were rated as the most comfortable, while the rear approaches and the front direct approach were rated as the least comfortable.

\section{c) Standing against the wall scenario:}

Non-parametric Friedman tests were carried out which found significant differences in mean comfort rating between the different approach directions $\left(\mathrm{Chi}^{2}(2)=9.33\right.$, $\mathrm{p}<.01)$. The Front Right and Front Left directions were rated as the most comfortable, while the Front Direct approach was rated as the least comfortable.

\section{d) Standing in the middle of the room scenario:}

Non-parametric Friedman tests were carried out which found significant differences in mean comfort rating between the different approach directions $\left(\mathrm{Chi}^{2}(5)=72.36\right.$, $\mathrm{p}<.001$ ). The Front Right and Front Left directions were rated as the most comfortable, while the Rear approach was rated as the least comfortable.

\section{e) Summary:}

There were significant differences between the different approach directions in all of the scenarios. The most preferred and least preferred approach directions (i.e. with the highest and lowest comfort ratings) are reported below in table 4. More details of the approach directions results are reported in [19].

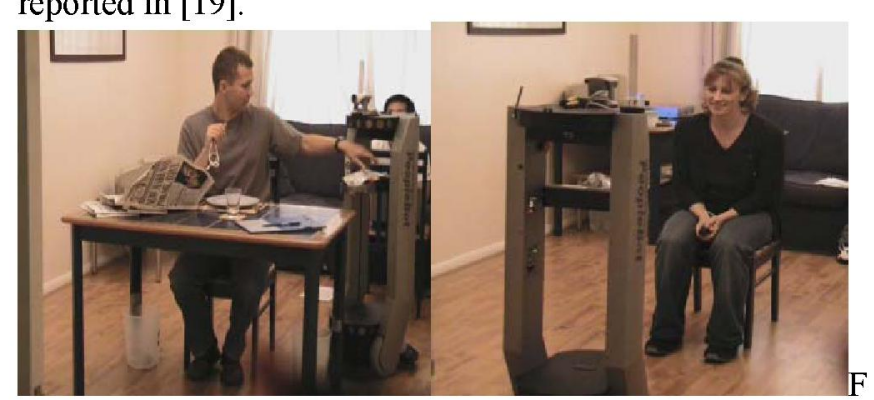

Fig 4. Participant seated behind table (left) and without table (right). Robot approaches from behind (left) and front (right).

TABLE 4 PREFERRED APPROACH DIRECTION BY SCENARIO

\begin{tabular}{llll}
\hline Scenario & $\begin{array}{l}\text { Most } \\
\text { Approach Direction }\end{array}$ & $\begin{array}{l}\text { Preferred } \\
\text { Approach Direction }\end{array}$ \\
\hline $\begin{array}{l}\text { Seated behind a } \\
\text { table }\end{array}$ & Front Sides & Rear Sides \\
$\begin{array}{l}\text { Seated without table } \\
\text { Standing against } \\
\text { wall } \\
\text { Standing }\end{array}$ & $\begin{array}{l}\text { Front Sides } \\
\text { Front Sides }\end{array}$ & $\begin{array}{l}\text { Rear, Front Direct } \\
\text { Front Direct }\end{array}$ \\
\hline \hline
\end{tabular}

\section{B. Personality Traits:}

The reliability of the Personality traits was assessed using Cronbach's Alpha'. The scores are reported below in table 5 .

\footnotetext{
${ }^{1}$ Cronbach's alpha measures how well a set of items (or variables) measures a single unidimensional latent construct. When data have a
} 
TABLE 5 PERSONALITY TRAITS RELIABILITY RATNGG

\begin{tabular}{ll}
\hline Trait & Cronbach's Alpha \\
\hline Extraversion & .896 \\
Agreeableness & .592 \\
Conscientiousness & .762 \\
Emotional Stability & .781 \\
Intellect/Imaginatio & .766 \\
n & \\
\hline \hline
\end{tabular}

These results confirmed the questionnaire used as a reliable tool for measuring these traits.

\section{Demographics, Personality traits and comfort ratings}

The relationship between demographics, personality factors and comfort ratings were initially assessed using Spearman's non-parametric correlation. No consistent pattern of significant correlations was found. During further examination of the data, a non-significant yet consistent trend appeared for extraversion. Extraversion seemed to be negatively or not correlated with the approach directions rated the most comfortable and positively correlated for the approach directions rated the least comfortable. This means that extroverts tend to rate the overall least comfortable approach direction (cf. Table 4) as more comfortable than introverts, and the overall most comfortable approach direction less comfortable than introverts. While extroverts still tended to prefer the overall most comfortable directions, the difference between the comfort ratings was much smaller than for introverts. To display this trend, tables 6-9 show the difference between participants scoring below and above the median score for extraversion, and figures 5-8 shows the mean comfort ratings for the approach directions for the participants scoring in the highest and lowest quartiles of extraversion. The effect size of this difference was too small to be significant for this sample size, but the consistency of this trend across the scenarios made us consider it more closely.

TABLE 6 REPORTED COMFORT RATINGS FOR SEATED AT TABLE SCENARIO

\begin{tabular}{llrr}
\hline \hline & & $\begin{array}{c}\text { Front side } \\
\text { Approach }\end{array}$ & $\begin{array}{c}\text { Rear } \\
\text { Approach }\end{array}$ \\
\hline Low extraversion & Mean & 4.6000 & 2.8500 \\
& $\mathrm{~N}$ & 10 & 10 \\
& Std. Deviation & .45947 & 1.61675 \\
\hline High Extraversion & Mean & 4.0455 & 3.5500 \\
& $\mathrm{~N}$ & 11 & 10 \\
& Std. Deviation & .98627 & 1.32183 \\
\hline Total & Mean & 4.3095 & 3.2000 \\
& $\mathrm{~N}$ & 21 & 20 \\
& Std. Deviation & .81358 & 1.48146 \\
\hline
\end{tabular}

TABLE 7 REPORTED COMFORT RATINGS FOR SEATED NO TABLE SCENARIO

\begin{tabular}{llrrr}
\hline \hline & & $\begin{array}{c}\text { Front Side } \\
\text { Approaches }\end{array}$ & $\begin{array}{c}\text { Front Direct } \\
\text { Approach }\end{array}$ & $\begin{array}{c}\text { Rear } \\
\text { Approaches }\end{array}$ \\
\hline Low Extraversion & Mean & 4.2857 & 3.00 & 3.6429 \\
& $\mathrm{~N}$ & 7 & 7 & 7 \\
& Std. Deviation & .39340 & 1.155 & 1.37581 \\
\hline High Extraversion & Mean & 4.3077 & 3.77 & 3.3462 \\
& $\mathrm{~N}$ & 13 & 13 & 13 \\
& Std. Deviation & .59646 & 1.092 & 1.14354 \\
\hline Total & Mean & 4.3000 & 3.50 & 3.4500 \\
& $\mathrm{~N}$ & 20 & 20 & 20 \\
& Std. Deviation & .52315 & 1.147 & 1.20197 \\
\hline \hline
\end{tabular}

multidimensional structure, Cronbach's alpha will usually be low. It is regularly used to gauge the reliability of psychometric scales.
TABLE 8 REPORTED COMFORT RATNGS FOR STANDING AGAINST THE WALL SCENARIO

\begin{tabular}{llrr}
\hline & & $\begin{array}{c}\text { Front Side } \\
\text { Approach }\end{array}$ & $\begin{array}{c}\text { Front Direct } \\
\text { Approach }\end{array}$ \\
\hline Low Extraversion & Mean & 4.2500 & 3.20 \\
& $\mathrm{~N}$ & 10 & 10 \\
& Std. Deviation & 1.00692 & 1.135 \\
\hline High Extraversion & Mean & 4.0000 & 4.00 \\
& $\mathrm{~N}$ & 11 & 11 \\
& Std. Deviation & 1.00000 & 1.265 \\
\hline Total & Mean & 4.1190 & 3.62 \\
& $\mathrm{~N}$ & 21 & 21 \\
& Std. Deviation & .98621 & 1.244 \\
\hline \hline
\end{tabular}

TABLE 9 REPORTED COMFORT RATINGS FOR STANDING IN THE MIDDLE OF THE ROOM SCENARIO

\begin{tabular}{llrr}
\hline \hline Extraversion & & $\begin{array}{c}\text { Front } \\
\text { Approaches }\end{array}$ & $\begin{array}{c}\text { Rear } \\
\text { Approaches }\end{array}$ \\
\hline Low & Mean & 4.1111 & 2.6364 \\
& $\mathrm{~N}$ & 12 & 11 \\
& Std. Deviation & .60858 & .65751 \\
\hline High & Mean & 3.9259 & 3.0000 \\
& $\mathrm{~N}$ & 9 & 9 \\
& Std. Deviation & .52116 & .72648 \\
\hline Total & Mean & 4.0317 & 2.8000 \\
& $\mathrm{~N}$ & 21 & 20 \\
& Std. Deviation & .56671 & .69585 \\
\hline \hline
\end{tabular}

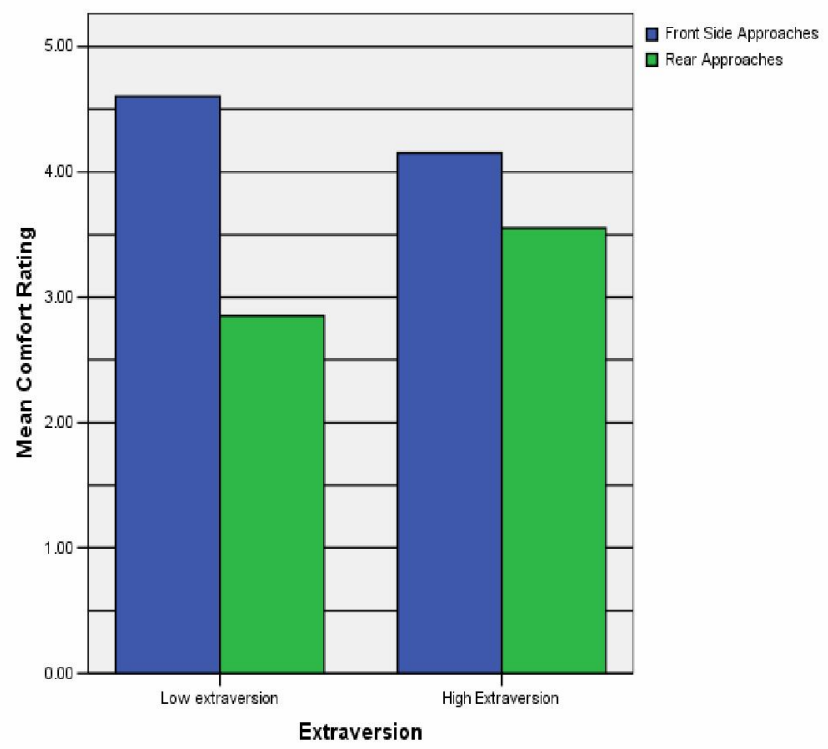

Fig 5. Mean comfort rating for most and least overall preferred directions for highest and lowest quartiles of extraversion scorers in "seated behind a table' scenario.

\section{Discussion}

When interpreting these results, it is important to note that the effect sizes were too small to be significant in this sample size. In this study, the role of personality, as measured using the Big Five Model, is a minor one, when determining the participants' comfort ratings across the different approach directions. This suggests that user preferences for this aspect of robot navigation in the vicinity of humans are more dependent on norms for interactions that the participants had 


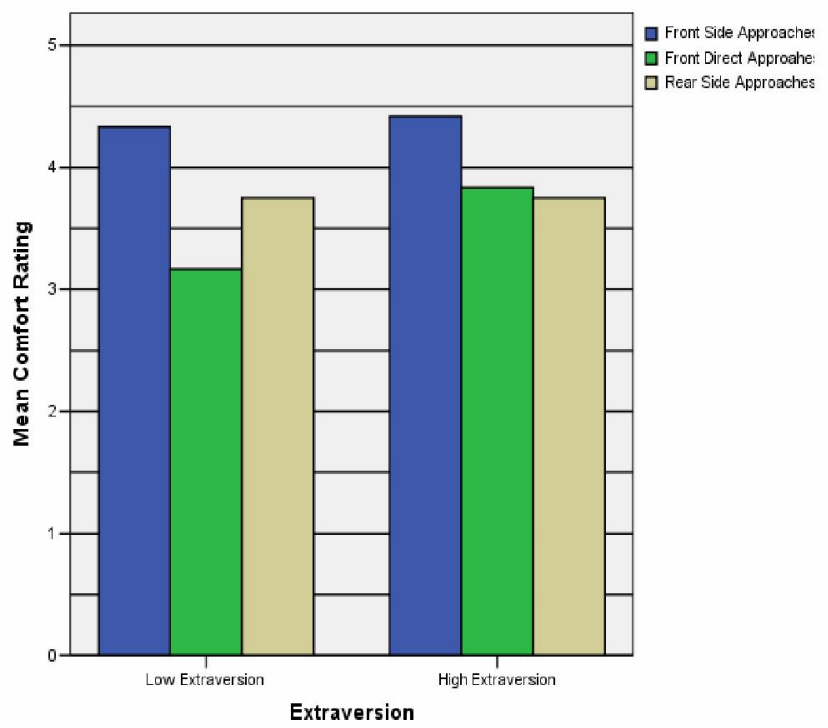

Fig 6. Mean comfort rating for most and least overall preferred directio. for highest and lowest quartiles of extraversion scorers in 'seated without table' scenario.

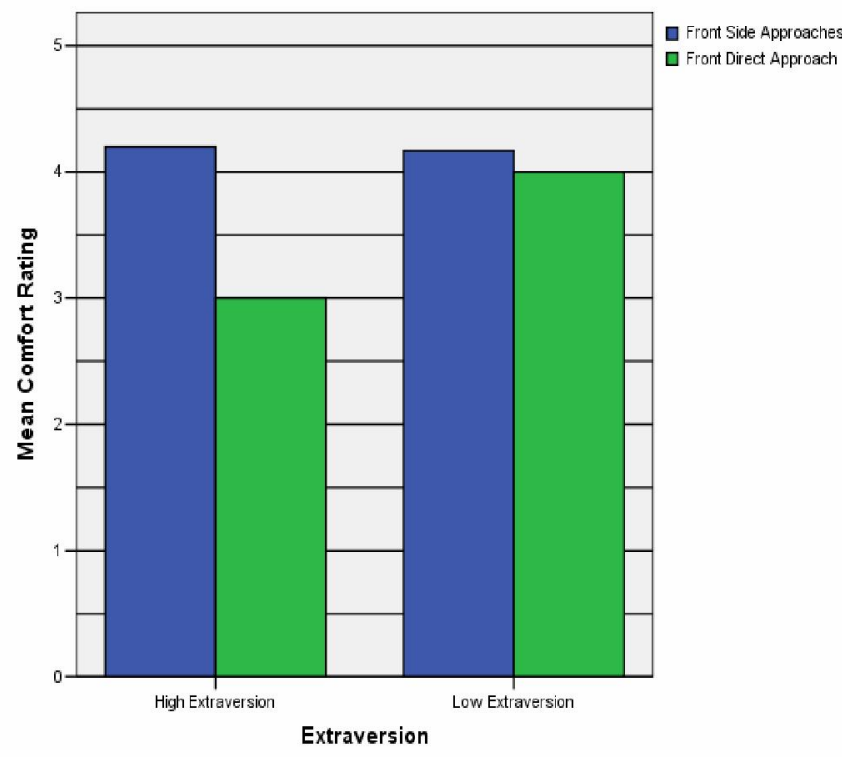

Fig 7. Mean comfort rating for most and least overall preferred directions for highest and lowest quartiles of extraversion scorers in 'standing in the middle of the room

in common rather than individual differences in personality However, this is a new area of research with few previous research results to compare with $[4,11]$.

The results nevertheless show a non-significant but consistent trend which raises some questions. The results are comparable to the effect of extraversion found in [15], as in both studies the participant made no decisions as to the preferred behaviour of the robot, but rather rated it after it had occurred. The similar, yet small effect in both studies suggests that a similar mechanism underlies these results. This is a promising result since two studies carried out by two independent research groups found the same trend in different HRI scenarios.

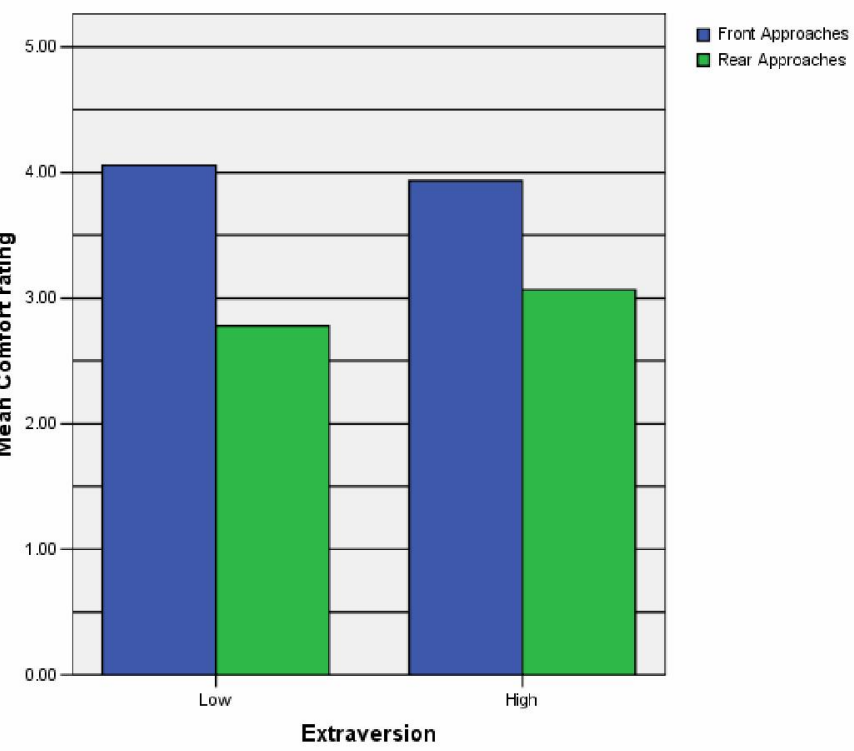

Fig 8. Mean comfort rating for most and least overall preferred directions for highest and lowest quartiles of extraversion scorers for 'standing in the middle of the room scenario.

However, at first glance, it would seem as if our findings reported in this paper contradict our previous results [3], as the extraversion factor in The Big Five model has many similarities with the 'Proactive' factor, which like Extraversion is highly negatively correlated with shyness and positively correlated with excitement seeking and impulsiveness. This factor was associated with participants coming less close to the robot while Extraversion in this study seemed to indicate a higher degree of tolerance for the overall least preferred directions. There were however important differences between these two studies that may account for the divergent results. The most important aspect is that of interactivity. In Walters et al. [3], the decision regarding personal space was made by the participant, the subject was either approaching a standing robot, or controlling a robot's approach distance. In contrast, in the current study, no choice was made by the individual participant: Regardless of the preferences of the participants, the robot approached from specific directions and the subject's preferences were asked afterwards.

As there were clear preferences in the sample as a whole, it appears that certain approach directions were deemed more appropriate than others by the participants, approaches from directions that were seen as less appropriate would be considered a breach of the norms of social interactions, akin to a violation of personal space. Research on personal space and the Introversion/Extraversion dimensions of personality in human-human interaction has previously shown that while there is little difference in the size of personal space, Extroverts are much more comfortable with this personal space being violated [20]. Also, higher levels of extraversion are associated with a higher degree of social competence. Research has found that social competence is correlated with tolerance to intrusions of personal space [21]. This could be due to several factors, extroverts may tend to seek out and 
enjoy social interactions more than introverts, and be more secure and flexible in a variety of social settings [17]. Applied to our research, it could imply that this general social security and flexibility could possibly lead to less discomfort for robot approach directions that were not appropriate.

In conclusion, it seems that while personality traits do not have any major impact upon what robot approach direction subjects prefer, higher extraversion scores are associated with slightly higher degrees of tolerance to robot behaviour that is less appropriate for the situation. Moreover, a comparison with the results by Walters et al. [3] suggests that this trend may be characteristic for scenarios where the 'robot is in control' (approaching a passive subject), while in scenarios that put the 'subject in control' of the robot's approach distances/directions an opposite effect can occur, as reported in [3] regarding proactiveness. The main difference between these two scenarios might be related to different levels of 'control', 'interactivity' (does the situation involve or afford interactivity), but could also lie in the differences between subjective self reports both prior to interactions (used in [14]) and in post-interaction evaluation (used in [3]), and observed behaviour during an interaction trial.

One implication from these results is that both 'live' decisions as to appropriate robot behaviour as well as postexperiment ratings given by participants are necessary to get more accurate insights into what is appropriate robot behaviour and how users will respond to, and feel about inappropriate behaviour. Unraveling details of these dependencies and relationships between subject personalities and robot behaviour poses many methodological and robotics challenges and results cannot be expected to come easily. However, this direction of research holds the promise to lay foundations for the development of truly personalised robot companions [6].

[1] Cogniron, http://www.cogniron.org, 2006.

[2] K. L. Koay, M. L. Walters, S. N. Woods, and K. Dautenhahn, "Empirical Results from Using a Comfort Level Device in Human-Robot Interaction Studies.," Proc. HRIO6, pp. 194-201, 2006.

[3] M. L. Walters, K. Dautenhahn, R. T. Boekhorst, K. L. Koay, C. Kaouri, S. Woods, C. Nehaniv, D. Lee, and I. Werry, "The influence of subjects' personality traits on personal spatial zones in a human-robot interaction experiment," Proc. 14th IEEE International Workshop On Robot And Human Interactive Communication (RO-MAN 2005), pp. 347-352, 2005.

[4] S. Woods, K. Dautenhahn, and J. Schulz, "The design space of robots: Investigating children's views," Proceedings, 13th IEEE International Workshop On Robot And Human Interactive Communication(RO-MAN 2004), pp. 47-52, 2004

[5] K. Dautenhahn, S. Woods, M. Walters, K. L. Koay, C. Nehaniv, E. Sisbot, R. Alami, and T. Simeon, "How may I serve you? A robot companion approaching a seated person in a helping context.," Proc. HRIO6, Salt Lake City, Utah, USA, pp. 172-179, 2006.

[6] K. Dautenhahn, "Robots We Like to Live With? - A Developmental Perspective on a Personalized, Life-Long Robot Companion," Proceedings of the I3th IEEE International Workshop on Robot and Human Interactive Communication(ROMAN 2004), pp. 17-22., 2004.
R. Opperman, Adaptive User Support. Hove, UK: Lawrence Erlbaum Associates, 1994.

E. Abrahamian, J. Weinberg, M. Grady, and C. M. Stanton, "The effect of personality-aware computer-human interfaces on learning," Journal Of Universal Computer Science, vol. 10, pp. 27-37, 2004

I. Graziola, F. Pianesi, M. Zancanaro, D. Goren-Bar, and, "Dimensions of adaptivity in mobile systems: personality and people's attitudes," Proceedings of the 10th international conference on Intelligent user interfaces, Jamuary 10-13, 2005, San Diego, California, USA, 2005.

[10] R. Rickenberg and B. Reeves, "The Effects of Animated Characters on Anxiety, Task Performance, and Evaluations of User Interfaces.," Proceedings of the ACM CHI 2000 Human Factors in Computing Systems Conference., pp. 49-56., 2000.

[11] J. Goetz and S. Kiesler, "Cooperation with a Robotic Assistant," CHI '02 Conference on Human Factors in Computing Systems, 2002.

[12] P. Wu and C. Miller, "Results from a field study: The need for an emotional relationship between the elderly and their assistive technologies," in Foundations Of Augmented Cogniton, Vol 11. Mahwah: Lawrence Erlbaum Assoc Publ, 2005, pp. 889-898.

[13] T. Nomura and T. Kanda, "On proposing the concept of robot anxiety and considering measurement of it.," Proceedings, 12th IEEE International Workshop on Robot and Human Interactive Interactive Communication(RO-MAN 2003), pp. 373-378., 2003.

[14] T. Nomura, T. Kanda, and Y. Suzuki, "Experimental Investigation into Influence of Negative Attitudes toward Robots on Human-Robot Interaction," AI\&Society, vol. 20, 2006.

[15] R. Gockley and M. J. Mataric', "Encouraging Physical Therapy Compliance with a Hands off Mobile Robot," Proc. HRI06, Salt Lake City, Utah, USA, 2006, pp. 150-155, 2006.

[16] L. R. Goldberg, " A broad-bandwidth, public domain, personality inventory measuring the lower-level facets of several five-factor models.," Personality Psychology in Europe, vol. 7, pp. 7-28, 1999.

[17] G. Matthews, I. J. Deary, and M. C. Whiteman, Personality Traits. Cambridge, UK: Cambridge University Press, 2003.

[18] M. Walters, S. Woods, K. L. Koay, and K. Dautenhahn, "Practical and methodological challenges in designing and conducting interaction studies with human subjects.," $A I S B^{\prime} 05$ Symposium on Robot Companions Hard Problems and Open Challenges in Human-Robot Interaction, pp. 110-120, 2005.

[19] S. Woods, M. Walters, K. L. Koay, and K. Dautenhahn, "Methodological Issues in HRI: A Comparison of Live and Video-based Methods in Robot to Human Approach Direction Trials," Proceedings, 15th IEEE International Workshop On Robot And Human Interactive Communication(RO-MAN 2006), In Press

[20] J. L. Williams, "Personal space and its relation to extraversionintroversion," Canadian-Journal-of-Behavioural-Science, vol. 3, pp. 156-160, 1971

[21] Y. Bar Haim, O. Aviezer, Y. Berson, and A. Sagi, "Attachment in infancy and personal space regulation in early adolescence," Attachment-and-Human-Development, vol. 4, pp. 68-83, 2002. 